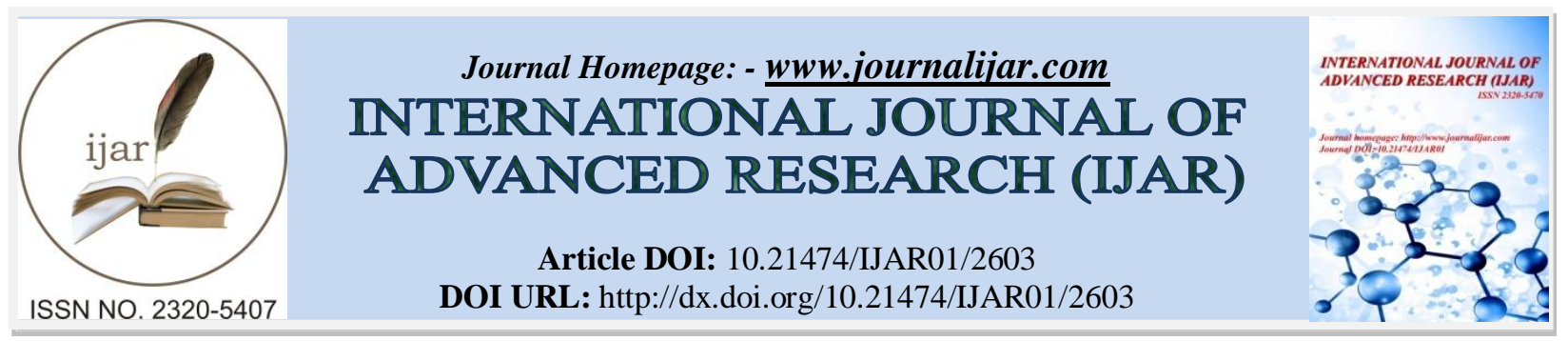

RESEARCH ARTICLE

\title{
ROLE OF FDP WORKSHOPS IN ADVANCEMENT, DEVELOPMENT AND TRANSMISSION OF KNOWLEDGE OF HIGHER EDUCATION FACULTY MEMBERS.
}

\begin{abstract}
Madhulata.
Research Scholar, BPSMV, Khanpur Kalan, Sonepat.

\section{Manuscript Info}

Manuscript History

Received: 28 October 2016

Final Accepted: 27 November 2016

Published: December 2016

\section{Abstract}

The Indian government is continuously introducing reforms to improve the standards of education, to meet the changing needs of the students, and to satisfy the demands of the workplace. Professors today are required to display different types of roles and responsibilities for their professional growth. Time requires the change as with time composition of students, technology and environment is changing with which professors have to adapt with. Keeping all this in mind faculty development programmes are arranged. Researcher has tried to find out effectiveness of FDP workshops through a questionnaire filled from ninety $(\mathrm{N}=90)$ faculty members who attended FDP workshops in Delhi which were selected conveniently and purposely from the three workshops organized in Delhi at different times and at different locations thirty members from each were selected as subjects. It was found that FDP workshops have significant positive effect.
\end{abstract}

Copy Right, IJAR, 2016,. All rights reserved.

\section{Introduction:-}

The Indian government is continuously introducing reforms to improve the standards of education, to meet the changing needs of the students, and to satisfy the demands of the workplace.

India's higher education structure is the third major in the world, next to the United States and China. Indian higher education system has expanded at a rapid pace by adding nearly 20,000 colleges and more than 8 million students in a decade from 2000-01 to 2010-11. The 12th Five-Year Plan, 2012-17, focus on quality education in the chapter of Inclusive \& Qualitative Expansion of Higher Education of the UGC document. There is a greater need of research and teaching - learning which should be encouraged to encounter the context and needs of our society, knowledge and the challenge of successful fostering of Constitutional values.

MHRD the Department of Higher Education is responsible for the overall development of the basic infrastructure of Higher Education sector, both in terms of policy and planning. The main focus of department is to look after qualitative improvement in the Higher Education, through world class Universities, Colleges and other Institutions.

The Kothari Commission (1964-66) suggested that a sound programme of professional education is essential for teachers to enhance the qualitative improvement of education. The commission recommended conduct of programmes sponsored by the UGC in universities. Such programmes aims at

1. conducting courses in professional institutes for different categories of teachers 
2. close collaboration with schools with a view to developing research and evolving better curricula and techniques of teaching

3. promoting research in education, especially with an interdisciplinary approach.

The commission also suggested the following principles for improving the quality of teacher education

$>$ Reorientation of subject-knowledge

$>$ Improvement in methods of teaching and evaluation

$>$ Improvement of student-teaching

$>$ Development of special courses and programmes

$>$ Revision and improvement of curricula.

Professors today are required to display different types of roles and responsibilities for their professional growth. Time requires the change as with time composition of students, technology and environment is changing with which professors have to adapt with.

Today the student body has become large and diverse on basis of different factors such as educational background, race and civilization, gender, class, age, and training. This growing diversity places more responsibilities on faculty members.

In 2007, Gappa et al. discussed the factors which have important implications on faculty members and the reasons due to which it become necessary for teachers to strive for professionalism development. The factors are-:

- Fiscal constraints and calls for accountability

- Increasing diversity of students

- The opportunities and challenges of technology

- Changes in faculty characteristics and shifts in appointment patterns

Statement of the problem:-

The Problem selected for investigation in the present study has been titled as "Role of FDP workshops in advancement, development and transmission of knowledge of higher education faculty members"

Objectives of the study:-

Why study FDP Workshops effectiveness:-

1. To know the reason for attending FDP workshops

2. To identify the knowledge enrichment and development through FDP workshops

3. To identify the transfer of knowledge to students by faculty attending FDP workshops

4. To offer recommendations that help to enhance results of FDP workshops

\section{Research questions:-}

The research Questions derived from these areas are as follows:

1. What is the purpose of faculties attending FDP workshops?

2. Do FDP workshops fulfill the purpose ?

3. Is knowledge gained through FDP workshops transferred to ones workplace ?

\section{Research hypothesis:-}

H1 FDP workshops significantly affect motivational level of participants

H2 FDP workshops significantly affect knowledge enrichment and development of participants

H3 FDP workshops participants significantly transfer knowledge attained during session

\section{Literature:-}

Kamel AM (2016) reported that high-quality professional training programs for staff members have become necessary in higher education institutions in order to compete the change.. Professional training programs or many FDPs have proven effective in developing faculty skills. Indeed, today, faculty development is a strategic need for institutional excellence and quality. 
C. Amundsen et al. (2005) through their analysis proposed four conceptual categories that distinguish among faculty development practices based on assumptions, Intended to represent what has emerged from their search of the literature.

Sarkar Arpita et al. (2008) found that the faculty have a constructive approach towards attending and applying the skills learnt in FDP'S. through their case study in Mumbai found faculty members were student oriented and wanted to transfer their skills to students .

Ozlem Sarikaya et al. (2010) by using self-assessment tools to assess the impact of a faculty development curriculum on the teaching skills. A faculty-training program consisted of "training skills" and "student evaluation instruments" courses. The impact of the curriculum was evaluated by self-reporting of faculty members (a total of 225 reports) $1-2$ yr after the program. Both courses were found to be beneficial by nearly all of the participants.

Bhatnagar kavita et al. (2010) reported analyses of the outcomes of efforts to revise health professions curriculum have identified the availability and effectiveness of faculty development as a predictor of the success or failure of reform initiatives.

As Bodily (2008) emphasizes faculty as the heart and soul of a university provide valuable skills and promote intellectual stimulation. Several studies have shown that faculty-student interaction leads to positive cognitive and affective maturity, increased determination in college, and an overall positive college experience (Astin 1993; Pascarella and Terenzini 1991).

Mildred M. Pearson (2005) findings from this study show positive changes in approaches to teaching through faculty development practices at Eastern Illinois University.

Dahlstrom, Eden (2015) Found that almost 7 out of 10 institutions (69\%) provide student technology assistants to help faculty use technology. After looking at the relationship between educational technology staffing patterns and faculty and student impressions of their technology experiences, found that educational technology staffing has a significant effect on student perceptions.

Melodie A. Rowbotham (2015) findings shows statistically significant results between the control and intervention groups and the pre- and post-mean scores, but no statistically significant changes in the scores over time in general or between the groups themselves. which indicates that participation in a faculty development program can influence how faculty feel about their role as a teacher and can increase teacher self-efficacy, but there is not a change in teacher self-efficacy as a whole or just by group.

Faculty development programs play an important role in helping faculty members to successfully play their roles to satisfy need of their profession. Faculty members who participated in a faculty development program found to have improved student success and student retention (Perez, McShannon, \& Hynes, 2012), and also have a positive impact on student knowledge, contentment, and motivation (Ambrosino \& Peel, 2011; Trigwell, Rodriguez, \& Han, 2012)

\section{Materials and Methods:-}

To achieve the objective of the study, ninety $(\mathrm{N}=90)$ faculty members who attended FDP workshops in Delhi were selected conveniently and purposely from the three workshops organized in Delhi at different times thirty members from each were selected as subjects. Questionnaire was used to measure purpose and effectiveness of FDP .In order to examine the hypothesis1 of the present study non parametric test Friedman was applied to know motive to attend FDP different variables of construct which were on likert scale were compared and to examine hypothesis 2 and 3 Cochran's Q test was applied as different statements of construct were in yes and no form. 
Results and Discussion:-

Table 1:-

\section{Ranks}

\begin{tabular}{|l|l|}
\hline & Mean Rank \\
\hline Teachers attend FDP for knowdege enhancement & 1.75 \\
\hline teachers attend FDP for confidence building & 2.45 \\
\hline Teachers attend FDP for Improving presentation skills & 4.46 \\
\hline Teachers attend FDP for getting API scores & 5.29 \\
\hline Teachers attend FDP for competitive advantage & 5.34 \\
\hline Teachers attend to equip themselves for changes in curriculum & 4.48 \\
\hline Teachers attend FDP for network building & 4.22 \\
\hline
\end{tabular}

\begin{tabular}{|l|l|}
\hline Test Statistics $^{\mathbf{a}}$ \\
\hline $\mathrm{N}$ & 90 \\
\hline Chi-Square & 257.429 \\
\hline Df & 6 \\
\hline Asymp. Sig. & .000 \\
\hline a. Friedman Test & \multicolumn{2}{|l|}{} \\
\hline
\end{tabular}

Results show that due to knowledge enrichment participants are motivated so alternative hypothesis is accepted. Mean rank of knowledge enrichment 1.75 shows respondents are highly satisfied with FDP workshops agreeing to its help in knowledge enhancement. Confidence building respondents lies in between agree to neutral, for presentation skills lies between neutral to disagree, for API score respondents strongly disagree the purpose of attending is not the score again for competitive advantage strongly disagree, change in curriculum between disagree to strongly disagree and same for network building.

Table 2:-

\begin{tabular}{|l|l|l|}
\hline Frequencies & Value \\
\hline & 1 & 2 \\
\hline Developing research culture & 75 & 15 \\
\hline Team Spirit for better decision-making & 43 & 47 \\
\hline Hands on experience on latest IT skills including softwares & 68 & 22 \\
\hline Peer groups to reinforce course learning & 30 & 60 \\
\hline Opportunity for one-to-one interaction & 53 & 37 \\
\hline Updated knowledge and information & 60 & 30 \\
\hline Course content coverage & 53 & 37 \\
\hline
\end{tabular}

\begin{tabular}{|l|l|}
\hline Test Statistics \\
\hline $\mathrm{N}$ & 90 \\
\hline Cochran's Q & $99.596^{\mathrm{a}}$ \\
\hline df & 4 \\
\hline Asymp. Sig. & .000 \\
\hline
\end{tabular}




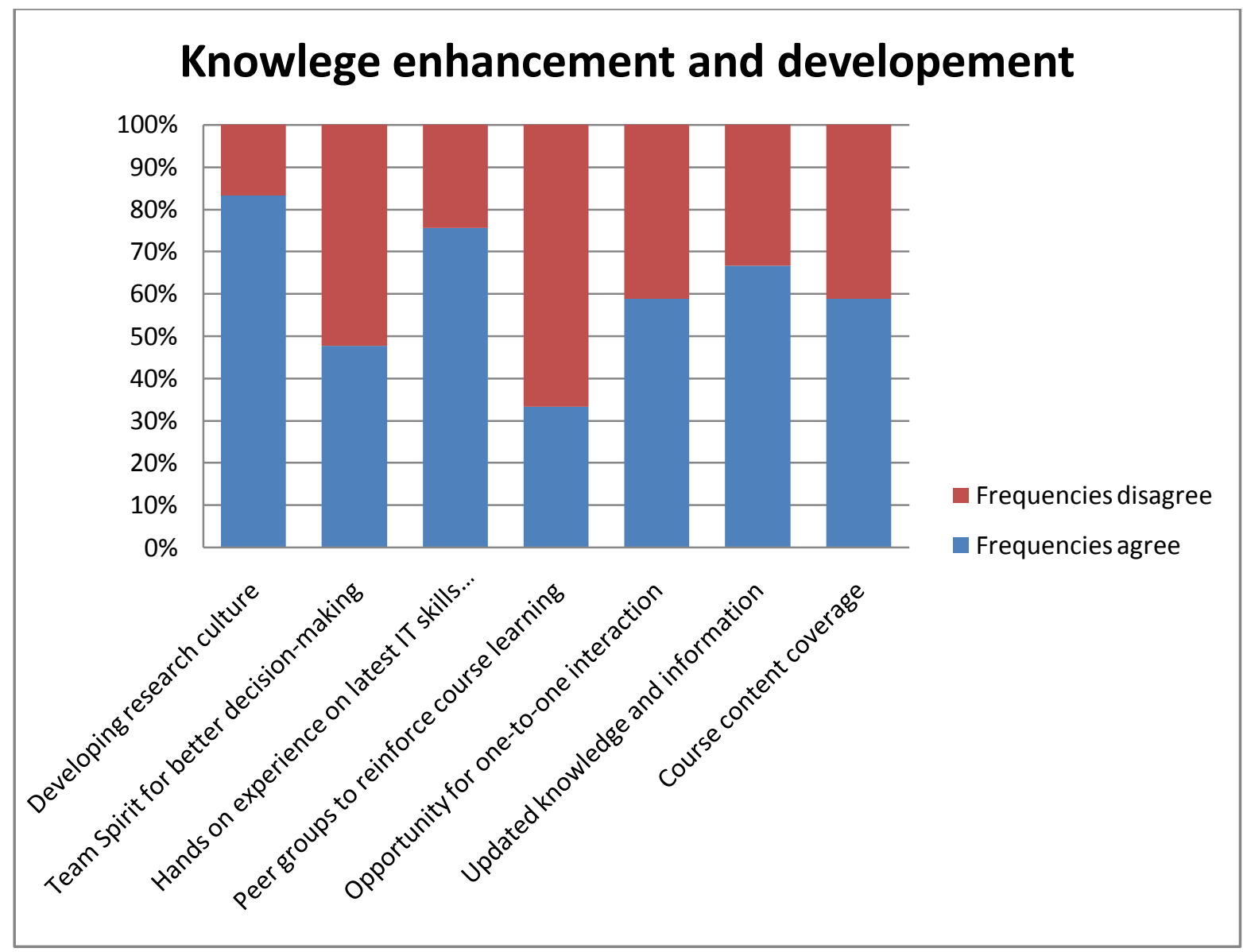

Results shows that 75 participants agree FDP helps in developing research culture, 43 agree for its help $\mathrm{n}$ team spirit for better decision making, 68 says FDP helps giving hands on latest IT skills including softwares, 60 disagree with effectiveness in peer group to reinforce course learning,53 agrees with opportunities for one to one interaction, 60 says FDP helps in updating knowledge and information, 53 agrees with that the course designed to be covered in FDP's is covered.

Table 3:-

\begin{tabular}{|l|l|l|}
\hline \multicolumn{2}{|l|}{ Frequencies } & Value \\
\hline & 1 & 2 \\
\hline Participation in curriculum development & 21 & 69 \\
\hline Undertaking innovative research projects & 74 & 16 \\
\hline Using diverse teaching method to improve learning & 39 & 51 \\
\hline Publication of research articles/papers in journals & 71 & 19 \\
\hline Organising seminars/debates/talks, etc. & 67 & 23 \\
\hline
\end{tabular}

\begin{tabular}{|l|l|}
\hline Test Statistics \\
\hline $\mathrm{N}$ & 90 \\
\hline Cochran's Q & $99.596^{\mathrm{a}}$ \\
\hline df & 4 \\
\hline Asymp. Sig. & .000 \\
\hline
\end{tabular}




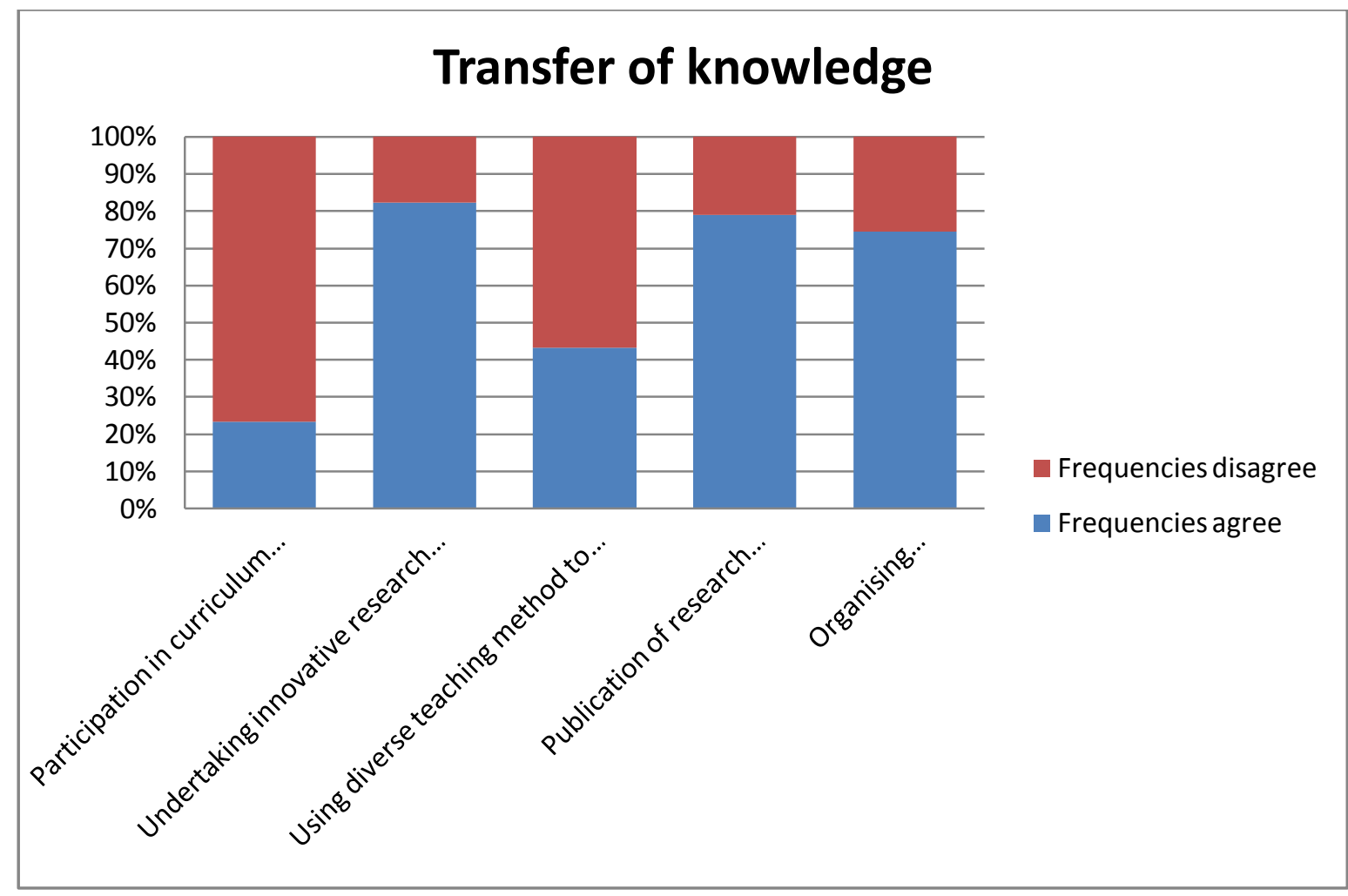

Result shows that only 21 agree that the knowledge attained in FDP's is transferred or revealed in curriculum development, 74 agrees its help in undertaking innovative research projects, only 39 agrees its use in diverse teaching methods to improve learning, 71 agrees it assist in publication of research papers, 67 agrees with transferring through organizing seminars/debates/talks etc.

\section{Conclusions:-}

1. Research hypothesis 1 is accepted by rejecting null hypothesis as the FDP's helps in motivating participants according to the purpose, among which knowledge enrichment was found to be most strongest and the weakest was purpose of attending FDP for API score

2. Research hypothesis 2 is accepted by rejecting null hypothesis as the FDP workshops significantly affect knowledge enrichment and development of participants as mostly agree that it develop research culture and least agree peer group development through these

3. Research hypothesis 3 is accepted by rejecting null hypothesis as FDP workshops participants significantly transfer knowledge attained during session highest transfer in innovative research projects and least transferred through curriculum developments

\section{References:-}

1. Kamel AM. Role of faculty development programs in improving teaching and learning. Saudi J Oral Sci [serial online] 2016 [cited 2016 Dec 20];3:61-8. Available from: http://www.saudijos.org/text.asp?2016/3/2/61/188073

2. Gappa JM, Austin AE, Trice AG. Rethinking Faculty Work: Higher Education's Strategic Imperative. San Francisco CA: Jossey-Bass; 2007.

3. Astin, A. 1993. What matters in college? Four critical years revisited. San Francisco: Jossey-Bass.

4. Bodily, B. 2008. Perceptions of faculty development: A study of a North Texas community college. PhD diss. University of North Texas Digital Collections.

5. Pascarella, E., and P. Terenzini. 1991. How college affects students: Findings and insights from twenty years of research. San Francisco: Jossey-Bass.

6. Dahlstrom, Eden. Educational Technology and Faculty Development in Higher Education. Research report. Louisville, CO: ECAR, June 2015. Available from http://www.educause.edu/ecar. 
7. Rowbotham, M. A. (2015). The impact of faculty development on teacher self-efficacy, skills and retention (IERC FFR 2015-1). Edwardsville, IL: Illinois Education Research Council at Southern Illinois University Edwardsville.

8. Perez, A. M., McShannon, J. \& Hynes, P. (2012). Community college faculty development program and student achievement. Community College Journal of Research and Practice, 36(5), 379-385.

9. Ambrosino, R., \& Peel, J. (2011). Faculty development programs: Assess the impact on instructional practices, and student learning and motivation. Journal of Faculty Development, 25(2), 33-38.

10. Trigwell, K., Rodriguez, K.C., \& Han, F. (2012). Assessing the impact of a university teaching development programme. Assessment \& Evaluation in Higher Education, 37(4), 499-511.

11. Amundsen et al. The What and Why of Faculty Development in Higher Education: An In-depth Review of the Literature 2005

12. Ozlem Sarikaya, Sibel Kalaca, Berrak Cali The impact of a faculty development program: evaluation based on the self-assessment of medical educators from preclinical and clinical disciplines Advances in Physiology Education Published 1 June 2010 Vol. 34 no. 2, 35-40 DOI: 10.1152/advan.00024.2010

13. Kavita Bhatnagar, Kalpana Srivastava, and Amarjit Singh Is faculty development critical to enhance teaching effectiveness?Ind Psychiatry J. 2010 Jul-Dec; 19(2): 138-141.doi: 10.4103/0972-6748.90349

14. Melodie A. Rowbotham, Southern Illinois University Edwardsville The Impact of Faculty Development on Teacher Self-Efficacy, Skills and Perspectives ISSUE 012015 